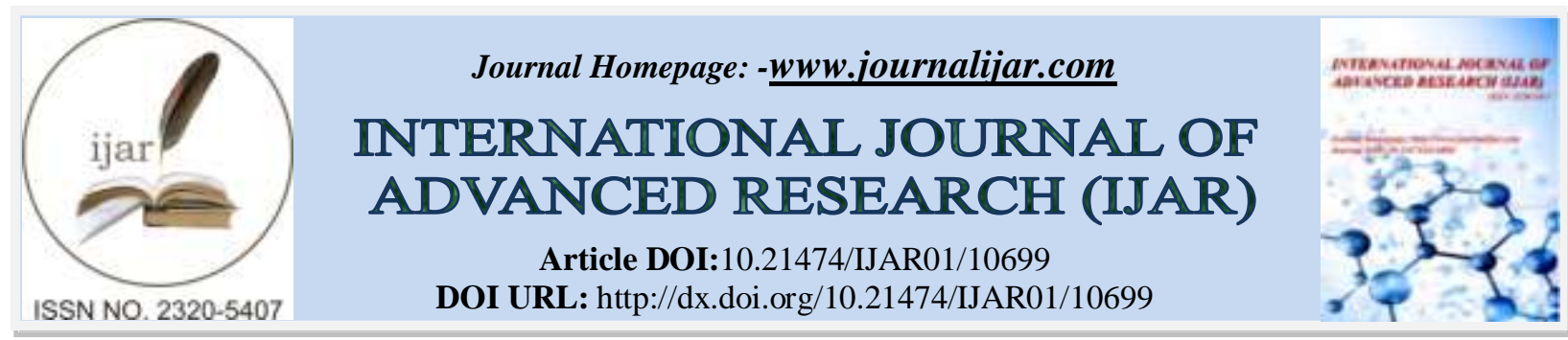

RESEARCH ARTICLE

\title{
CURRENT SITUATION OF ENERGY JUSTICE AND ANALYSIS OF APPROACHES TO MEASURING ENERGY POVERTY: CASE STUDY OF BENIN(A REVIEW)
}

\section{Latif A. Fagbemi ${ }^{1}$, Evrard K. Ekouedjen ${ }^{1}$ and David G. Adamon ${ }^{2}$}

1. Laboratoire d'Energétique et de Mécanique Appliquée (LEMA,), Ecole Polytechnique d'Abomey-Calavi, Ecole Doctorale des Sciences de l'Ingénieur, Université d'Abomey-Calavi.

2. Université Nationale des Sciences Techniques Ingénierie et Mathématiques.

\section{Manuscript Info}

Manuscript History

Received: 20 January 2020

Final Accepted: 22 February 2020

Published: March 2020

\section{Key words:-}

Energy policies, Energy Justice, Energy Poverty, Energy Efficiency, Developing Countries

\begin{abstract}
Energy justice and energy poverty are booming concepts in West Africa and in Benin. This paper presents a literature review on both energy justice in Benin and on energy poverty measurement approaches. Evidence suggests that in developing countries, energy poverty is related to access to modern and affordable energy sources. They also indicate that energy injustices happen in Benin and are not perceived everywhere in the same way. Perception differs according to geographical location, social status and gender. Results showed that $60.63 \%$ of surveyed people hadn't been consulted by the government about energy policies making. In the other hand, energy poverty is favored by low income, high energy costs and inefficiency or low energy efficiency. Beninese consumes very little electricity (about 3\%), a lot of biomass (51\%) and the rest in hydrocarbons (46\%). According to (International Energy Agency, 2017) Benin has an electricity access rate of $32 \%$ compared with an average of $52 \%$ for West Africa. This rate is $11 \%$ in rural areas and $56 \%$ in urban areas. The multidimensional index of energy poverty (MEPI) reveals that Benin with a score of 0.83 is energy poor. It also shows that energy efficiency remains the surest way of improving energy justice. The disparities in access to energy noted will be measured in future studies with appropriate measurement methods adapted to the context of Benin that will be developed including equipments energy efficiency.
\end{abstract}

Copy Right, IJAR, 2020,. All rights reserved.

\section{Introduction:-}

Energy is at the heart of our lives and no human development is possible without it. While there is no Millennium Development Goal (MDG) for energy, access to energy is now considered by the international community as a necessary condition for achieving the Millennium Development Goals (MDGs) related to poverty and hunger reduction, health, gender equality and education (UN Energy and UN-Energy, 2005). Jeffrey Sachs said that without increased investment in the energy sector, the MDGs will not be achieved in the poorest countries (Modi et al., 2005). The right to access energy services thus derives from the fundamental right of all citizens to claim universal human rights (United Nations, 1948).. In the same way as access to food or health, the right to energy is a decisive element for the emancipation and development of peoples, for the reduction of inequalities. In fact, Goal 7 of the Sustainable Development Goals illustrates this right so well by aiming at "Ensuring access for all to reliable, 
sustainable and modern energy services at an affordable cost" (United Nations, 2015). Access to energy has therefore become a civil right. Access to clean energy is not only an environmental problem, but also a civil right (Bagenal, 2017).

However, according to the International Energy Agency and the World Bank (Sustainable Energy For All Global Tracking Framework, 2017), nearly 1.6 billion people currently live without access to electricity, with a low rate of electrification in rural areas in 2014. In 2016, has increased to 1.1 billion people without access to electricity and the majority of those without access to electricity are in developing countries in Asia and sub-Saharan Africa (IEA, 2017). According to the International Energy Agency and the World Bank Mondiale (Sustainable Energy For All Global Tracking Framework, 2017), about $80 \%$ of this number of people without access to electricity live in only 20 countries. This situation is all the more favored by the strong demographic growth. People without electricity are increasingly concentrated in this area (Asia and sub-Saharan Africa). According to forecasts by the International Energy Agency, in 2030, 600 million of the 674 million people without access to electricity live in sub-Saharan Africa, the majority of them in rural areas (IEA, 2017). The energy resources of the planet are therefore not equitably distributed. The problem of energy injustice thus posited favors energy poverty, which particularly affects the countries of sub-Saharan Africa, which constitutes an obstacle to the development of this region of the world. The concepts of energy justice and energy poverty are relatively new in Africa in general and in Benin in particular. Very few authors at the national level have addressed these issues. It is therefore necessary to take stock of what is being done in the world in this sense and to draw inspiration from it to propose methods and tools adapted to the national and sub-regional context, making it possible to measure the extent of energy injustices and energy poverty to address it.

This article is therefore in line with advancing the concepts of energy justice and energy poverty in Benin, by identifying the causes, the local particularities and possible tracks for their improvement. This article is organized into seven sections. The first section identifies the research problem and presents the objectives and relevance of the study. The second section presents the methodology used to perform the literature review. The third section and the fourth section present the synthesis of publications that addressed the concept of energy justice and and describe the current situation of energy justice in Benin. The fifth section deal with energy poverty measurement indicators. The sixth onepresents the main indices used in the literature to measure energy poverty. The seventh section presents a short review on energy poverty in Benin. The last section summarizes all that is done and presents the conclusions and perspectives.

\section{Méthodology:-}

The methodology used to conduct this literature review consisted of reviewing journals proposing topics related to energy justice and/or energy poverty. Among these topics we note articles on the concept of energy justice, energy poverty and the measurement indices of energy poverty. To better assess the level of energy justice in Benin, data from the African Energy Justice Survey conducted in Benin by Econoler during February-March 2019 were used. These surveys covered about 640 households spread over the Beninese territory. Six regions out of the twelve regions of Benin were part of this survey and were chosen randomly as well as about twenty towns or cities (see Figure 1). In addition, national reports dealing with issues of energy access and energy efficiency are also available. The following sections describe the main conclusions of the publications reviewed. In order to highlight the strengths and weaknesses of the different methods of measuring energy poverty discussed in the literature and to draw on them to develop a tool specific to the national context, a SWOT analysis that assesses the strengths, weaknesses, opportunities and threats is carried out. 


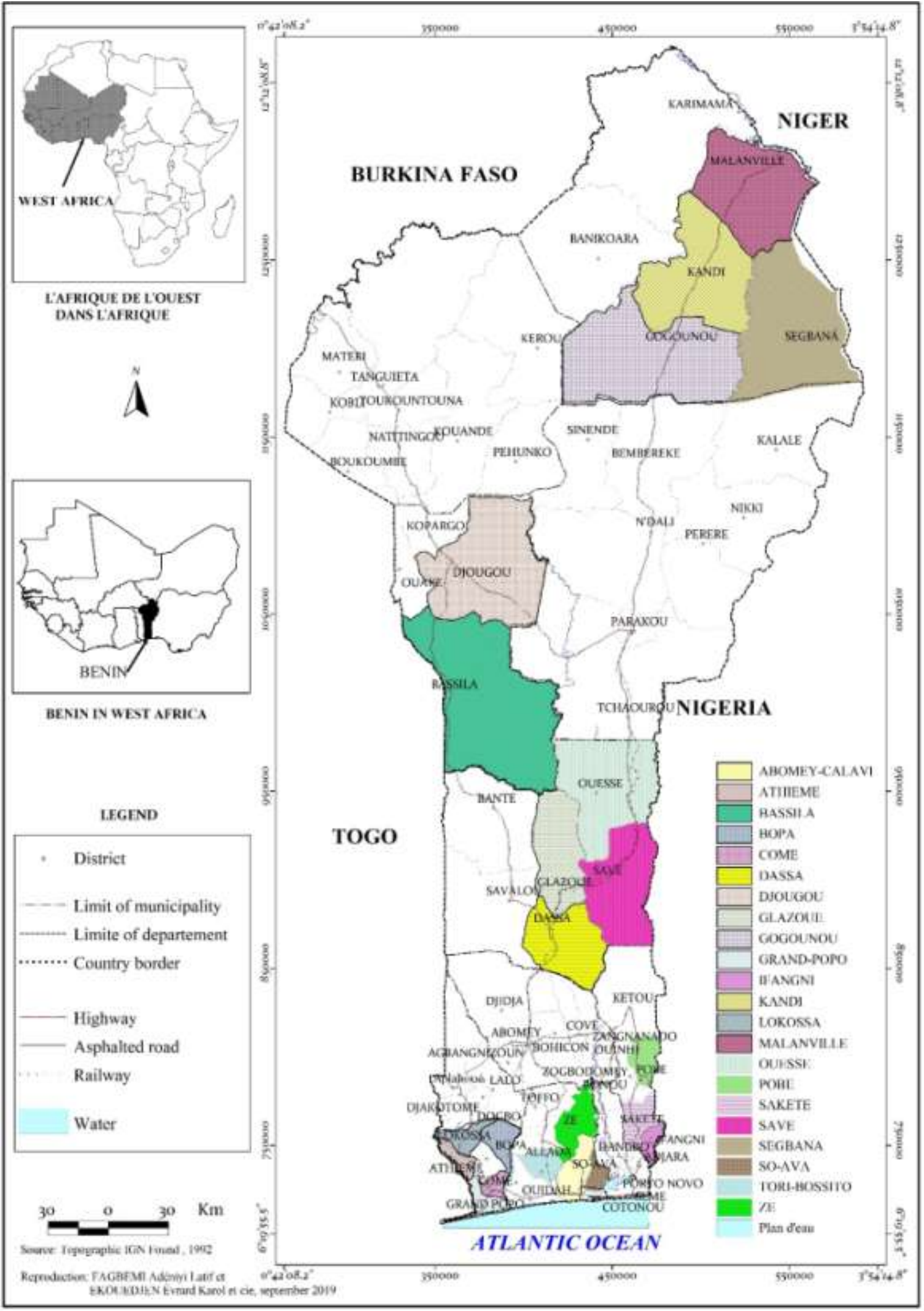

Figure 1:- Study area localization. 


\section{Energy justice:}

Historically, energy justice has its roots in the environmental justice movement and adopts the same basic philosophy. The environmental justice movement began in North America in the 1970s in response to the uneven distribution of environmental problems, pollution and waste management facilities, and the associated risks. These were most often located next to poor and black communities (Jenkins et al., 2014). Energy justice has therefore emerged with the aim of "providing all individuals, in all fields, with safe, affordable and sustainable energy" (McCauley et al., 2013). There are few autonomous definitions or objectives for energy justice, and universal adoption of a single definition is unlikely (Joroff, 2017). Energy justice therefore advocates for a fair sharing of the benefits and benefits of energy services and systems and for more inclusive decisions (Jenkins et al., 2016). It can be used as a framework to identify when, where and how injustices occur in energy systems and how injustices can be eliminated (Simcock and Mullen, 2016). Energy justice is an important analytical tool for energy researchers who strive to understand how values fit into energy systems or solve common energy problems. Energy justice is a useful decision-making tool that can help energy planners and consumers make more informed energy choices (Sovacool and Dworkin, 2015). Energy justice provides a framework for perceiving disparities in our energy system (LaBelle, 2017).

Energy justice, like its counterpart in environmental justice, is based on three (03) principles of modern justice (Heffron and McCauley, 2014 ; Bickerstaff, Bulkeley and painter, 2009) distributive justice, procedural justice and recognition justice. In addition to the three basic principles, some authors indicate that cosmopolitan justice is also proposed (Sari et al., 2017).

\section{Distributive justice:}

Distributive justice concerns not only the establishment of infrastructure, but also access to energy services. From a consumption point of view, the program to combat energy poverty has revealed the extent of charges for affordable access to energy services. In this respect, energy justice concerns both physical access to heating or cooling and electricity (Jenkins et al., 2016). It is based on the distribution of energy as a social good and studies where the damage of the supply of energy is posed as a social problem. Distributive justice encourages researchers to investigate where energy injustices are emerging around the world (Jenkins et al., 2016).

\section{Procedural justice:}

Procedural justice advocates for fair procedures that engage all stakeholders without discrimination. It stipulates that all segments of the population should be able to participate in decision-making and that their decisions should be taken into account. It also requires the participation, impartiality and full disclosure of information by government and industry and appropriate and sympathetic engagement mechanisms (Jenkins et al., 2014).It is a call for fair procedures involving all stakeholders without discrimination. Procedural justice is supported by access to, and pressure from, multilevel legal systems (Jenkins et al., 2016). Procedural justice involves significant participation, impartiality, the disclosure of complete information by government. It involves also industry and appropriate and sympathetic participation mechanisms. In this context, for example, it should be noted that many governments place public consultation at the center of energy strategy and environmental decision-making(Jenkins et al., 2016).

\section{Recognition Justice:}

The last principle of energy justice is the recognition justice. It is often seen as an essential element of procedural justice however, recognition implies not only fair and effective participation(Jenkins et al., 2014) but also, it is more than just tolerance. It argues that individuals must be fairly represented, that they must be free from physical threats and that they must be offered full and equal political rights. A lack of recognition can take various forms of cultural and political domination, insults, degradation and devaluation. It can manifest itself not only as a failure to recognize, but also as a misunderstanding of a distortion of people's opinions that may seem degrading or despicable. Thus, recognition justice includes appeals to recognize divergent perspectives rooted in social, cultural, ethnic, racial and gender differences (Jenkins et al., 2016).

\section{Cosmopolitan justice:}

In addition to the three basic principles, there is also a cosmopolitan justice (Jenkins et al., 2016), a fourth principle of the energy justice framework. This principle states that energy justice is not just a national problem, but that injustice is a universal problem that affects all human beings in all nations. This represents ethical responsibilities applicable to all agents capable of understanding, facilitating and acting on them. (Jenkins et al., 2016)(Jenkins, McCauley and Warren, 2017) also underline the importance of this far-reaching approach in developing a 
comprehensive framework for taking energy justice into account in an energy system, and applying the basic principles to each element of the energy life cycle as a whole supply chains of the energy market.

\section{Current situation of energy justice in Benin:}

In Benin, electricity represents about $3 \%$ of national energy consumption compared to about $51 \%$ of biomass and $46 \%$ for fossil fuels. Serious consequences are linked to the use of biomass both in terms of health and environment. In sub-Saharan Africa, $43 \%$ of the population now has access to electricity (IEA, 2017) while in Benin we are around $32 \%$ in 2016 according to the same source. A third of Benin's population of more than a dozen million inhabitants has access to electricity, with disparities between rural and urban areas. In 2016, more than half of people living in urban areas $(56 \%$ ) have access to electricity while only $11 \%$ of rural dwellers have access to it (International Energy Agency). This illustrates a disparity in access to electricity that contradicts what distributive justice recommends. In addition to limited access, Benin's electricity distribution network is characterized by - many power cuts (planned interruptions, rationing and unscheduled cuts) - Voltage instability that can damage equipment and often requires the use of an expensive voltage stabilizer to fix it.These findings contrast with the recommendations in the Energy Justice Decision Support Tool(Sovacool and Dworkin, 2015), which states that people deserve sufficient high quality energy resources. The insufficiency of the supply of electrical energy both in terms of quality and quantity is the result of three problems; Insufficient supply of energy to cover the demand, poor financial situation and operating conditions of the national electric power distribution company (Benin Electric Power Company, SBEE), and mismanagement of the entire energy sector.

Poor households are vulnerable in terms of access to energy. Table 1 shows the consumption levels of the different forms of electrical energy in poor and vulnerable households(Millenium Challenge Account, 2018). This table clearly shows that the richest households spend significantly more income (74\%) in the payment of their connection to the SBEE than the poor households $(9 \%)$. On the other hand, poor households invest more in other forms of energy (kerosene lamps, flashlights). In addition, expenditure items for cooking energy sources meet the same rule (charcoal $57 \%$ and gas $14 \%$, for rich households, wood collected $79 \%$ and for poor households, wood collected 14\%) (Millenium Challenge Account, 2018). These observations disagree with the principles of distributive justice and recognition justice.

Table 1:- Sources of Lighting and Energy by Poverty Level and Food Consumption.

\begin{tabular}{|c|c|c|c|c|c|c|c|c|c|}
\hline \multirow{2}{*}{$\begin{array}{c}\text { Food } \\
\text { consumptio } \\
\text { n group }\end{array}$} & \multicolumn{4}{|c|}{ Main source of household lighting } & \multicolumn{5}{|c|}{$\begin{array}{l}\text { Main source of energy for household cooking and food } \\
\text { processing }\end{array}$} \\
\hline & $\begin{array}{l}\text { ElectricitySBE } \\
\mathrm{E}\end{array}$ & $\begin{array}{l}\text { Oil } \\
\text { lam } \\
\mathrm{p}\end{array}$ & $\begin{array}{c}\text { Batter } \\
\mathrm{y} \\
\text { torch }\end{array}$ & $\begin{array}{l}\text { Othe } \\
\text { r }\end{array}$ & $\begin{array}{l}\text { Purchase } \\
\text { d wood }\end{array}$ & $\begin{array}{l}\text { Collecte } \\
\text { d wood }\end{array}$ & $\begin{array}{c}\text { Charco } \\
\text { al }\end{array}$ & $\mathrm{Ga}$ & Other \\
\hline $\begin{array}{c}\text { Poor } \\
\text { Consumptio } \\
\mathrm{n}\end{array}$ & $9 \%$ & $\begin{array}{l}61 \\
\%\end{array}$ & $30 \%$ & $1 \%$ & $14 \%$ & $79 \%$ & $6 \%$ & $\begin{array}{l}0 \\
\%\end{array}$ & $1 \%$ \\
\hline $\begin{array}{c}\text { Limit } \\
\text { Consumptio } \\
\mathrm{n}\end{array}$ & $17 \%$ & $\begin{array}{l}50 \\
\%\end{array}$ & $32 \%$ & $1 \%$ & $14 \%$ & $70 \%$ & $15 \%$ & $\begin{array}{l}0 \\
\%\end{array}$ & $1 \%$ \\
\hline $\begin{array}{c}\text { Acceptable } \\
\text { Consumptio } \\
n\end{array}$ & $25 \%$ & $\begin{array}{l}49 \\
\%\end{array}$ & $14 \%$ & $2 \%$ & $16 \%$ & $58 \%$ & $24 \%$ & $\begin{array}{c}1 \\
\%\end{array}$ & $2 \%$ \\
\hline The poorest & $7 \%$ & $\begin{array}{l}56 \\
\% \\
\end{array}$ & $36 \%$ & $1 \%$ & $10 \%$ & $84 \%$ & $5 \%$ & $\begin{array}{l}0 \\
\%\end{array}$ & $0 \%$ \\
\hline $\begin{array}{l}\text { The most } \\
\text { rich }\end{array}$ & $74 \%$ & $\begin{array}{l}17 \\
\% \\
\end{array}$ & - & - & $8 \%$ & $15 \%$ & $57 \%$ & $\begin{array}{l}15 \\
\% \\
\end{array}$ & \\
\hline
\end{tabular}

Regarding procedural justice, surveys of nearly 640 households indicate that 388 households (60.63\%) stated that they had not been consulted in the past on behalf of the government to take their opinions into account or energy needs in a national project or law while 212 households $(33.13 \%)$ report having been consulted. The rest of the households say they do not know. This proves that the Beninese government is weakly consulting the people at the grassroots for making energy decisions. 
Also, the study on human resources at the SBEE conducted by the Cabinet GECA in 2013 shows inequalities between women and men both in terms of technical positions and management (Millenium Challenge Account, 2018). The report mentions that there are 4 times more men than women in the workforce. This institution had only one woman among the 14 central directors, none of the four experts having central director ranks, only one woman among the 23 regional directors; on the other hand, $46.7 \%$ of women heads of agencies, which is almost parity. The age pyramid shows that the SBEE is less confronted with a problem of staff aging than that of gender balance. Men occupy in each of the three technical bodies (electricity, mechanics, common), more than 2/3 of the workforce - the common body has 279 women, or about $30 \%$ of the total number of this body; - the body of the Electricians, 12 women, or $3 \%$ of the total strength of this body and; - the mechanics' corps, one (1) woman, that is about $1 \%$ of the body's strength.

\section{Energy poverty: \\ Definitions of energy poverty:}

Firstly, it should be noted that despite the various efforts made by the international scientific community, to date, there is no standard definition of energy poverty. The terminology of "fuel poverty" was born in the United Kingdom in the 1970s under the guiding of militant associations and personalities who alerted the authorities of a growing risk of winter mortality following the rise in prices of oil. 'energy. Energy poverty is a highly subjective and relative notion, since it is defined in relation to what can be considered an "acceptable situation" (EPEE, 2009). The work of the European EPEE team (EPEE, 2008 ; EPEE, 2009) and the work of some authors as (Devalière, 2007), note that fuel poverty refers to three interlocking notions: the social and economic situation of a household (conjunctural or structural ), the state of its housing and its thermal quality, and its supply of energy (access, cost, quality), in a context of housing crisis.

In France, the definition of energy poverty was introduced by Law No. 2010-788 of 12 July 2010 on the national commitment to the environment known as the "Grenelle 2 Act" (Ii et al., 2010), which has itself amended Act No. ${ }^{\circ}$ 90-449 of May 31, 1990 aimed at the implementation of the right to housing (Besson law). Thus energy poverty is defined as follows: "Is in a situation of fuel poverty under this law a person who experiences in his housing particular difficulties to have the supply of energy necessary to satisfy his basic needs because the inadequacy of its resources or housing conditions.".

Energy poverty can also be defined as lack of access to reliable and modern energy resources. Two main elements make it possible to define energy poverty in a household: income and energy consumption. It is important to note that energy poverty in developing countries is primarily a problem of adequate physical access to clean and modern energy while energy poverty in developed countries is more a matter of accessibility, quality and energy efficiency (Bonatz et al., 2018). According to the Africa Energy Commission (Nzobadila, 2017). Energy poverty can be defined according to three (03) approaches: the economy-based approach, the engineering approach and the access to energy approach (Pachauri et al., 2004).

\section{Approaches based on the economy:}

The most common approaches to measuring energy poverty are those involving the definition of an energy poverty line. For this purpose, the economy-based approach is developed and used for the first time in the UK (Boardman,1991 ; The UK Fuel Poverty Strategy, 2003). According to the latter, a household that spends more than $10 \%$ of its income for the satisfaction of its energy needs is in a situation of energy poverty. This approach is used by several authors (Foster, Tre and Wodon, 2000) who used household survey data from Guatemala to calculate the "energy poverty line". In this work, they define the poverty line as the average energy consumption in all households whose total consumption expenditure per inhabitant is within a range of plus or minus $10 \%$ of the official poverty line. (Johansson, 2002) define energy poverty as part of the energy budget, that is, the share of household expenditure or income spent on fuel and electricity.

The problem with such a measure is that the share of a household's energy budget often depends not only on the type of fuel or energy used and its market price but also on the efficiency and cost of the appliances needed to use specific energies (Pachauri et al., 2004). In addition, a large part of the budget could also be the result of high consumption, either because of high prices or the large size of households, further complicating the interpretation of this indicator (Foster, Tre and Wodon, 2000). 
In order to take into account the different efficiencies of the wide range of fuels used by households, another approach to comparing poor and non-poor households adopted by some authors (Leach, 1987 ; Foster, Tre and Wodon, 2000) is to estimate the "effective price" or " net price "defines as the price per unit of useful energy consumed. It is common for the poorest households to use the most expensive energies in terms of price per unit of useful energy, because using the most inefficient devices. Also, studies show that the poorest households depend on the most inefficient energies (Hosier and Kipondya, 1993). The poorest households are at a greater disadvantage than richer households when a comparison of the actual energy cost per unit of useful energy consumed also includes the time costs and transaction costs associated with the collection or exchange of energy. acquisition of fuels (Pachauri et al., 2004).

\section{Engineering-based approaches:}

Another approach to measuring energy poverty uses "engineering" estimates to determine the direct energy needed to meet basic needs. Studies (Revelle, 1976) cited in (Goldemberg, 1990) report technical-type calculations for estimating basic energy requirements. The same author has estimated that the primary direct energy requirement per unit time to satisfy basic needs is about $500 \mathrm{~W}$ per person. This type of calculation is based on assumptions about the type of equipment that uses energy, its size, efficiency and intensity of use. This approach requires a first normative step: the definition of a set of basic needs which needs vary according to the subjective needs, the climate, the period, the age, the sex etc.

\section{Energy poverty as access to energy:}

A number of authors (Bala, 1991 ; Davis, 1998) have defined energy poverty in terms of access to energy services. Access to energy is defined as "access to clean, reliable and accessible energy services for cooking, heating, lighting, healing, communicating and producing" (AGECC, 2010). The International Energy Agency (IEA) defines access to energy as reliable and affordable access to clean cooking facilities and electricity, sufficient to initially provide a basic set of energy services, and then a growing level of electricity to reach the regional average (IEA, 2017).

In 2016, 1.1 billion people have no access to electricity, and the majority of these are in developing countries in Asia and sub-Saharan Africa (IEA, 2017) as shown in the following figure.

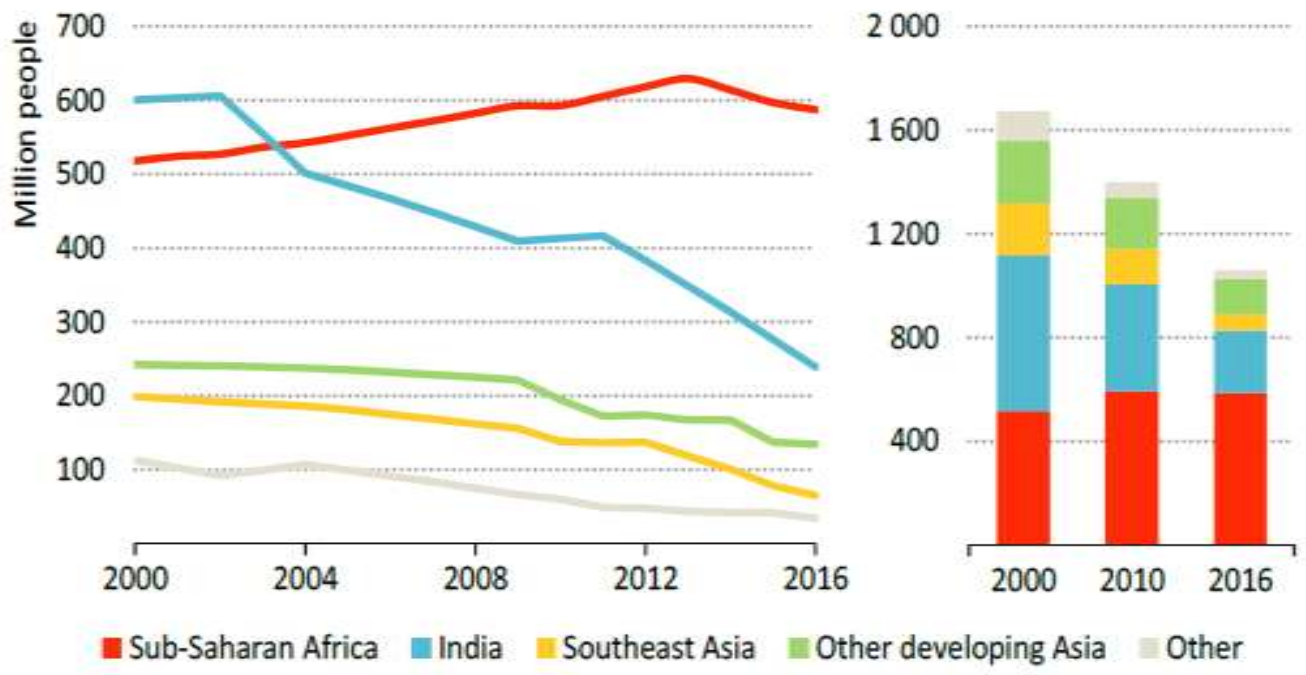

Figure 1:- Population without access to electricity by region (IEA, 2017).

\section{Causes of energy poverty:}

Several factors can explain energy poverty, these are discussed in this section. Energy poverty is a dynamic and complex process. The socio-economic situation of the household, the energy performance of housing and energy prices are important factors of energy poverty (Meyer et al., 2018). For several authors, (Bala, 1991 ; Palmer, 2008 ; Heffner and Campbell, 2011 ; Boardman, 2012 ; Legendre and Ricci, 2014 and Papada and Kaliampakos, 2018), energy poverty is due to the combined effect of three factors: Weakness of income (low income), High cost of energy and Energy inefficiency or low energy efficiency. Each of these factors is discussed later. 


\section{Weakness of income (low income):}

Low income is a factor that predisposes households to suffer from energy poverty. Studies show that the poorest households depend on the most inefficient energies (Bala, 1991). The poorest households are at a greater disadvantage than richer households when a comparison of the actual energy cost per unit of useful energy consumed also includes the time costs and transaction costs associated with the collection or exchange of energy. acquisition of fuels (Pachauri et al., 2004). The wider impacts of fuel poverty are felt by households and low-income communities (Bala, 1991). Low income is mainly linked to the country's economy and an improvement in income linked to economic policies reduces the number of poor people from an energy point of view. In 2005, in England, most of the 1.5 million households in fuel poverty were also in a situation of income poverty. This means that policies to reduce income poverty would have had a direct impact on household energy poverty (Bala, 1991).

\section{High cost of energy:}

It seems obvious that a low-income household has difficulty in obtaining energy if it is at a high price. The high cost of energy is therefore also a factor favoring energy poverty.Indeed, the majority of energy-poor households are located in rural areas or in the poorest regions of the world (Africa South of the Sahara, Asia, Latin America, etc [39]. These households have relatively low incomes and are unable to obtain modern energy supplies if they are expensive. The high cost of energy is therefore one of the main causes of energy poverty.

\section{Energy inefficiency or low energy efficiency:}

The price of energy and low income are important factors, but the crucial factor that promotes energy poverty is energy inefficiency (Bala, 1991). A low-income household that uses efficient equipment may not be in energy poverty; A household with a similar income, but using inefficient energy equipment, is likely to be low in energy. The problem stems from the inability of low-income households to save to invest in the property. If low income is linked to the country's economy and the high cost of energy is determined by energy producers, the energy efficiency of the equipment is the responsibility of the household. equipments to use. So intervention at this level would be more feasible while the other factors are the responsibility of the rulers.

\section{Energy poverty measurement:}

Several indicators are generally used to quantify or assess the energy poverty of a household. These are individual or one-dimensional indicators, sets of indicators or dashboards and composite indices (Nussbaumer, Bazilian and Modi, 2012). These are classified into three major groups and are discussed in the following paragraphs.

\section{Individual indicators or one-dimensional indices}

The first category of indicator is that of individual indicators or one-dimensional indices. Unidimensional indices provide a powerful, unbiased measure that is easy to interpret for a specific dimension and is simple to compute (Bersisa, 2016). However, he continues, they are not suited to less tangible issues such as sustainable development. One-dimensional clues are easy to manipulate and provide powerful, unbiased information that is easy to interpret with respect to a specific dimension (Nussbaumer, Bazilian and Modi, 2012). They are appropriate in certain specific cases (such as measuring the level of economic activity with GDP). Another example of this type of indicator is the index of Foster et al. (Foster, Tre and Wodon, 2000).

However, these measures present a narrow view of the problem under study and are often not adapted to less tangible problems such as sustainable development or poverty. Complex issues such as human development and poverty that are multidimensional in nature will instead be evaluated with other more appropriate tools such as individual indicator sets or composite indices.

\section{Measures composed of sets of indicators or "dashboards"}

This category of indicators gives a description, a much more complete representation of the problem studied. The Millennium Development Goals Indicator Program is an illustrative example that helps to track progress on the United Nations Millennium Declaration commitment with a battery of more than 60 indicators (Nussbaumer, Bazilian and Modi, 2012). ]. The Energy Indicators for Sustainable Development (IEDD) developed by the International Atomic Energy Agency (IAEA) (IAEA, 2005) are also included in this category of indicators. Another example of indicators in this category is the two-dimensional measure of energy poverty and distribution (Pachauri et al.,2004). 
While it is true that these indicators give a complete representation of the problem studied, it must be noted that they are not without limits. Indeed, assessing changes in a large number of indicators and drawing meaningful conclusions is not easy. Tracking trends over time, or making cross-country comparisons based on a "dashboard" of indicators, may be impractical. In some cases, it is useful to quantify multiple outcomes such as the incidence of multiple deprivations. Then we have to resort to another form of aggregation model (Nussbaumer, Bazilian and Modi, 2012).

\section{Composite indices}

Composite indices have been created as a compromise between the simplicity of one-dimensional indicators and the need to take into account the multidimensional nature of certain problems such as energy poverty. They represent an attempt to overcome the shortcomings of one-dimensional indicators while producing a result that condenses information into simple and easily interpretable indicators (Nussbaumer, Bazilian and Modi, 2012). Composite indices are single digits calculated from a number of variables that represent the aggregated value of a dimension that may be difficult to grasp (as is the case with sustainable development) on the basis of an underlying model. They are based on a set of sub-indicators that may or may not have common measures and aim to capture the multidimensional aspects of a problem that can not be described in a single indicator (Nussbaumer, Bazilian and Modi, 2012). Composite indices are advantageous over the one-dimensional approach where we evaluate each dimension with respect to predetermined limit points (Bersisa, 2016). In composite indexes, we find a unique number that essentially facilitates a comparison between different groups.

However, composite indices have some limitations. Indeed, by combining variables, the process includes a form of one-way reduction with all associated methodological issues and the required assumptions and simplifications that it implies (including value judgments) (Nussbaumer, Bazilian and Modi, 2012). According to the same source, composite indexes can be misleading in terms of policy, especially if the analysis of results is too simplistic or when the indicator is poorly constructed. Moreover, as an illustration, the Human Development Index (HDI) (Nations Unies, 1990), which is a composite index, has been the subject of much criticism in the literature (Høyland, 2009).

Composite indices measuring energy poverty include the Multidimensional Energy Poverty Index (MEPI), the Energy Development Index (EDI) (IEA, 2010) and the Energy Poverty Index (EPI). ) (Mirza and Szirmai, 2010). These are described in the following paragraphs. Table 1 below presents the SWOT analysis performed on each category of indicators

Table 2:- SWOT analysis of different categories of energy poverty indicators.

\begin{tabular}{|c|c|c|c|c|}
\hline $\begin{array}{l}\text { Category of } \\
\text { indicators }\end{array}$ & Strength & Weakness & Opportunity & Threat \\
\hline $\begin{array}{l}\text { One- } \\
\text { dimensional } \\
\text { indices }\end{array}$ & $\begin{array}{l}\text { - Unbiased } \\
\text { information for a } \\
\text { specific dimension } \\
\text { (Bersisa, 2016), } \\
\text { (Nussbaumer, } \\
\text { Bazilian and Modi, } \\
2012 \text { ) } \\
\text { interpret Easy to } \\
\text { 2016), (Nussbaumer, } \\
\text { Bazilian and Modi, } \\
\text { 2012) }\end{array}$ & $\begin{array}{l}\text { - Not suitable } \\
\text { for multidimensional } \\
\text { problems } \\
\text { (Nussbaumer, } \\
\text { Bazilian and Modi, } \\
2012 \text { ) }\end{array}$ & $\begin{array}{l}- \\
\text { - Simple } \\
\text { calculation (Bersisa, } \\
2016) \\
\text { handle }\end{array}$ & $\begin{array}{l}\text { - Close view } \\
\text { of the problem }\end{array}$ \\
\hline $\begin{array}{ll}\text { Sets } & \text { of } \\
\text { indicators or } \\
\text { "dashboards" }\end{array}$ & $\begin{array}{l}\text { - Full } \\
\text { representation of the } \\
\text { problem } \\
\text { (Nussbaumer, } \\
\text { Bazilian and Modi, } \\
\text { 2012) }\end{array}$ & $\begin{array}{l}\text { - Complex } \\
\text { (Nussbaumer, } \\
\text { Bazilian and Modi, } \\
\text { 2012) } \\
\text { - Tracking } \\
\text { trends over time } \\
\text { difficult } \\
\text { (Nussbaumer, } \\
\text { Bazilian and Modi, }\end{array}$ & - & $\begin{array}{l}\text { - Comparisons } \\
\text { between impassable } \\
\text { countries } \\
\text { (Nussbaumer, } \\
\text { Bazilian and Modi, } \\
2012 \text { ) }\end{array}$ \\
\hline
\end{tabular}




\begin{tabular}{|c|c|c|c|c|}
\hline & & 2012) & & \\
\hline $\begin{array}{l}\text { Composite } \\
\text { indices }\end{array}$ & $\begin{array}{l}\text { - Single } \\
\text { (Nussbaumer, } \\
\text { Bazilian and Modi, } \\
2012 \text { ) } \\
- \text { Indicator } \\
\text { uniqueness } \\
\text { (Nussbaumer, } \\
\text { Bazilian and Modi, } \\
2012 \text { ), (Bersisa, } \\
\text { 2016) Condenses } \\
-\quad \\
\text { the information into } \\
\text { simple and easy-to- } \\
\text { interpret indicators } \\
\text { (Nussbaumer, } \\
\text { Bazilian and Modi, } \\
\text { 2012) }\end{array}$ & $\begin{array}{l}\text { - Reduction } \\
\text { to a single measure } \\
-\quad \text { Implies } \\
\text { assumptions and } \\
\text { simplifications } \\
\text { (Nussbaumer, } \\
\text { Bazilian and Modi, } \\
\text { 2012) }\end{array}$ & $\begin{array}{l}\text { - Facilitates } \\
\text { comparison between } \\
\text { different groups } \\
-\quad \text { Capturing } \\
\text { the multidimensional } \\
\text { aspects of a problem } \\
\text { (Nussbaumer, } \\
\text { Bazilian and Modi, } \\
2012 \text { ) }\end{array}$ & $\begin{array}{l}\text { - Sometimes } \\
\text { misleading in case of } \\
\text { overly simplistic } \\
\text { analysis or when the } \\
\text { indicator is poorly } \\
\text { constructed } \\
\text { (Nussbaumer, } \\
\text { Bazilian and Modi, } \\
2012 \text { ) }\end{array}$ \\
\hline
\end{tabular}

From the SWOT analysis above, it can be concluded that although each category of indicators has particular strengths, the composite indices appear to be more effective and practical. They are a good compromise between the simplicity of one-dimensional clues and the complexity of dashboards. In fact, several authors (Serwaa, Kemausuor and Brew-hammond, 2015) and (Sanusi and Owoyele, 2016) have used composite indices to measure energy poverty.

\section{Common indices of energy poverty: \\ One-dimensional indices:}

Index of Foster et al. (Foster, Tre and Wodon, 2000)

The author proposes a simple one-dimensional method for measuring the energy price reduction that can be expected from access to electricity. This method provides estimates of the reduction in fuel poverty that could be achieved with better access to electricity. The measure of energy poverty proposed uses the first three (03) measures of (James Foster, 1984).

The 1st is the energy poverty index, which is the percentage of the population living in households whose energy consumption is below the energy poverty line. This is noted $P_{0}$.

The second measure reflects the intensity of energy poverty: it is the index of energy poverty gap noted $P_{1}$. He estimates the average distance separating the energy poor from the energy poverty line in proportion to this line.

The third measure quantifies the severity of energy poverty. This is the energy poverty gap index squared $P_{2}$. It takes into account not only the average distance between the energy poor and the energy poverty line in proportion to this line, but also the inequality between the poor.

Let $E_{i}$ be the energy consumption of the household i, z the energy poverty line, $\mathrm{N}$ the size of the population; $w_{i}$ the weight of the household $i$. It should be noted that the weight is the size of the household multiplied by the expansion factor, the sum of the weights being $\mathrm{N}$.

$$
P_{\theta}=\sum_{E_{i} \leq z}\left(\frac{w_{i}}{N}\right) *\left(1-\frac{E_{i}}{Z}\right)^{\theta}
$$

It is important to focus on taking into account the quality or efficiency of different fuels when measuring energy consumption. In order to be able to compare the different fuels, the corresponding energy expenditure is converted into a comparable unit, namely the energy consumption efficiency using the regional unit prices of the consumer price index of Guatemala, as well as the efficiency factors of United Nations (Nations Unies, 1987).

Let $P_{i k}$ be the market price or gross price of energy (fuel), $k=1, \ldots \ldots, K$ for the housework i, $C_{i k}$ household energy expenditure; $E F_{k}$ the energy efficiency factor reflecting the quality of the fuel $k ; E_{i k}$ is the amount of energy 
provided by the fuel $k$ in standard effective $\mathrm{kWh} ; E_{i}$ the total amount of energy provided by the different fuels for the household i.

$$
E_{i}=\sum_{k=1}^{K} E_{i k}=\sum_{k=1}^{K} \frac{C_{i k}}{\frac{P_{i k}}{E F_{k}}}
$$

In this equation, the net price per $\mathrm{kWh}$ effective for fuel $\mathrm{k}$ is:

Regarding the estimation of the energy poverty line, several methods can be used.

- One method is to calculate the average energy consumption of households whose total per capita consumption is within plus or minus $10 \%$ of the dollar (monetary poverty threshold used in the literature).

- A second method is to define all the basic energy needs. In Guatemala, energy experts have shown that a household should be able to run two $60 \mathrm{~W}$ bulbs and a $16 \mathrm{~W}$ radio for four hours each day. A household should also be able to use $5 \mathrm{logs}$ of firewood and $2 \mathrm{~kg}$ of wood every day for cooking. This leads to an energy poverty threshold of 2,154 kWh per year or $5.9 \mathrm{kWh}$ per day.Mesure de l'impact de l'accès à l'électricité sur la précarité énergétique. The average net price paid by households for each energy efficient $\mathrm{kWh}$ consumed is:

$$
P_{i}=\frac{\sum_{k=1}^{K} C_{k}}{\sum_{k=1}^{K}\left(\frac{C_{i k}}{P_{i k}}\right) * E F_{k}}
$$

Since electricity is much more efficient and cheaper than other fuels for lighting, households without access to electricity are likely to have a higher net price per kWh than those who do.

The average values of $P_{i}$ for those with access and those without access differ.

- $\quad$ Part of this difference may be due to the electricity itself

- $\quad$ Part may be due to other differences in characteristics between households.

To determine the marginal impact of access to electricity on energy prices by controlling other household characteristics, a regression analysis is needed.

Let $\mathrm{L}$ be a vector of geographical location variables; $\mathrm{H}$ is a vector of household residue characteristics including nominal variables of the quintile for the household's position in the per capita income distribution; $\mathrm{R}$ vector describing the physical characteristics of household residence of dummy variables for access to the electrical grid and $\mathrm{O}$, a vector of dummy variables to access other sources of energy.

$$
\log \left(P_{i}\right)=\beta_{0}+\beta_{1} L_{i}+\beta_{2} H_{i}+\beta_{3} R_{i}+\beta_{4} G_{i}+\beta_{5} O_{i}+\varepsilon_{i}
$$

A negative and statistically significant estimate of $\beta_{4}$ would suggest that access to electricity reduces energy efficient prices by $4 \%$. When households without access will have access to electricity their energy price would then be reduced to $P_{i}\left(1+\beta_{4}\right)$.

Suppose that the household's energy expenditure remains unchanged after the reduction in the price provided by access to electricity, the new consumption level is given by:

$$
E_{i} /\left(1+\beta_{4}\right)
$$

And we get:

$$
P_{\theta}=\sum_{E_{i} \leq z}\left(\frac{W_{i}}{N}\right) *\left[1-\frac{\frac{E_{i}}{1+\beta_{4}}}{2}\right]^{\theta}
$$

\section{Indices composed of sets of individual indicators or "dashboards":}

Two-dimensional measurement (Pachauri et al., 2004)

Thisl measure of energy poverty and energy distribution combines the elements of access to different types of energy and the amount of energy consumed. It provides a brief overview of the different approaches to measuring energy poverty and how indicators for energy access and consumption can be used for poverty measurement and as a reflection of the general level of human well-being.

The two-dimensional indicator of energy poverty and distribution introduces the so-called "Access Matrix - Energy Consumption" is a good complement to the conventional methods of energy-based income poverty measures commonly used. Consumption and access to energy have important social and environmental dimensions that are reflected in such a measure. Primary energy is energy embodied in natural resources that are extracted but has not been transformed. Then, end-use energy is the energy content of the energy supplied to the consumer at the point of end-use. The useful energy is the energy that has been transformed into the form required for actual use. Direct 
household demand is for energy services. To appreciate energy poverty, the level of energy services seems to be more appropriate. However, it may happens that services can't be measured in energy units, and they require many other things for delivery in addition to the energy vectors themselves. Thus, there is no way to distinguish energy services from other services and products. When it is not possible to measure energy services directly, agood approximation is to measure energy use. Useful energy analysis makes sense when comparing the different ways of providing a specific energy service but for different energy services is not appropriate.

Construction of the new two-dimensional measure of energy poverty:

The access information combined with the different energy vectors on the basis of the actual usage data is used. A major advantage of such an approach is that it measures not only consumption but also in a certain sense, capacity. The different steps of the construction of the measurement are described as follows.

Step 1 of the measure: estimate basic energy requirements for the average household.

Step 2: correct the economies of scale of households

Step 3: Group households according to the amount of useful energy they consume

Step 4: Group households according to their access to different energy vectors

Step 5: Access matrix - energy consumption. This matrix divides the population according to their access to different types of energy and the amount of useful energy per capita they consume.

Energy Indicators of Sustainable Development (IEDD) (IAEA, 2008)

The core set of energy indicators, now called Sustainable Development Energy Indicators (EIDDs), were designed to provide information on current trends in the energy field in a form that facilitates decision-making at the national level, in order to help countries to evaluate the effectiveness of their energy policies for sustainable development actions. Indicators should make it easier to see what programs are needed for sustainable development. They should identify which energy statistics should be collected, as well as the necessary scope of regional and national databases. Indicators of the core set of Sustainable Development Energy Indicators (EIDDs) are examined according to their dimensions, themes and sub-themes according to the same conceptual framework used by the United Nations Commission on Sustainable Development (CSD). There are 30 of them, divided into three dimensions (social, economic and environmental), subdivided into 7 themes and 19 sub-themes. It should be noted that some indicators may have more than one dimension, theme or sub-theme because of the many interactions between these categories. In addition, each indicator could represent a group of related indicators needed to evaluate a particular issue.

\section{Composite indices:}

Energy Development Index (EDI) (IEA, 2010)

The IEA has developed an Energy Development Index (EDI) to better understand the role of energy in human development. It tracks progress in transition from a country or region to the use of modern fuels. By publishing EDI updates annually, the IEA hopes that the international community will be aware of the problems of energy poverty and help countries to monitor their progress towards modern energy access. The EDI is calculated to reflect the UNDP Human Development Index and consists of four indicators, each representing a specific aspect of potential energy poverty:

Commercial energy consumption per capita: it serves as an indicator of the overall economic development of a country.

Electricity consumption per capita in the residential sector: indicator of the reliability of electricity services and the ability of consumers to pay.

Share of modern fuels in the total energy consumption of the residential sector: it serves as an indicator of the level of access to clean cooking facilities.

Share of the population with access to electricity.

A separate index is created for each indicator, using the actual maximum and minimum values for the developing countries studied. The performance of each indicator is expressed as a value between 0 and 1, calculated using the formula below, and the EDI is then calculated as a mathematical average of the four values for each country.

$$
\text { Indicator }=\frac{\text { realvalue }- \text { minimumvalue }}{\text { maximumvalue }- \text { minimumvalue }}
$$


The Table 3 below shows the maximum and minimum values used in the country calculations.

Table 3:- The minimum and maximum values used in the calculation of the 2010 energy development index (IEA, 2010).

\begin{tabular}{|l|c|c|}
\hline \multicolumn{1}{|c|}{ Indicator } & $\begin{array}{c}\text { Minimum value } \\
\text { (Country) }\end{array}$ & $\begin{array}{c}\text { Maximum value } \\
\text { (Country) }\end{array}$ \\
\hline Commercial energy consumption per capita (toe) & $\begin{array}{c}0,03 \\
\text { (Eritrea) }\end{array}$ & $\begin{array}{c}\text { (Libya) } \\
\text { (Venezuela) }\end{array}$ \\
\hline $\begin{array}{l}\text { Electricity consumption per capita in the } \\
\text { residential sector (toe) }\end{array}$ & $\begin{array}{c}0,001 \\
\text { (Haiti) }\end{array}$ & $\begin{array}{c}100 \\
\text { (Ethiopia) }\end{array}$ \\
\hline $\begin{array}{l}\text { Share of modern fuels in the total energy } \\
\text { consumption of the residential sector }(\%)\end{array}$ & $\begin{array}{c}11,1 \\
\text { (Yemen, Lebanon, Syria, Iran) }\end{array}$ \\
\hline $\begin{array}{l}\text { Share of population with access to electricity (\%) } \\
\text { (Jordan, Lebanon) }\end{array}$ \\
\hline
\end{tabular}

The choice of indicators is limited by the type of energy poverty data currently available. For example, the figure for commercial energy consumption per capita is an indicator of the overall economic development of a country but, for reasons of data insufficiency, it does not take into account biomass resources, particularly wood., coal and biofuels of the countries. Biomass data are rarely sufficiently disaggregated to capture this reality. With the introduction of high-efficiency, low-emission stoves, biomass consumption will decline in many countries. However, EDI can not adequately compensate for the fact that this decline will be slower than in countries where households use liquid fuels for cooking, even though the impact on energy poverty could be similar. The countries included in the EDI are those for which the IEA collects energy data.

Energy Poverty Index (EPI) (Mirza and Szirmai, 2010)

It is a composite index proposed by Pakistanis (Mirza and Szirmai, 2010) to measure the degree of energy poverty among rural households. It takes into account for the household, disadvantages related to the use of different sources of energy and its lack. This index takes into account the size of households. According to the authors, energy poverty is determined by two (02) elements:

The excessive inconvenience associated with the energy mix used by rural households

The lack of sufficient energy to meet the basic needs of households (the energy deficit).

As an innovative aspect, it combines existing energy deficit measures with measures of the disadvantages associated with the use of traditional energy sources.

Energy disadvantage refers to the degree of physical difficulties associated with the acquisition and use of an energy source to meet the energy needs of households. To measure these difficulties, the authors identified the following indicators:

1. Frequency of purchase or collection of a source of energy

2. Distance traveled by the household

3. Means of transport used

4. Household member's participation in the acquisition of energy

5. Time spent collecting energy per week

6. Household health

7. Children's participation in energy collection.

The calculation of the Energy Poverty Index involves the following steps:

Step 1: calculation of the inconvenience index for each disadvantage indicator.

The above indicators of inconvenience strongly depend on the number of people in the household. For this fact, we standardized three (03) inconvenience indicators by household size. These are the following indicators:

1. Frequency of purchase or collection of a source of energy

2. Participation of the household member in the acquisition of energy

3. Time spent collecting energy per week 
As household size increases, the household will have to spend more time collecting more firewood. We then divided the response scores on these indicators by the number of household members to control for the effect of household size. Other indicators are not affected by household size.

Using the HDI methodology (Nations Unies, 1990), the general formula for calculating the index is:

\section{With :}

$$
X_{h i j}=\frac{R_{h i j}-R_{i j}(\min )}{R_{i j}(\max )-R_{i j}(\min )}
$$

$\mathrm{R}$ is the score of the answer to a question about energy drawbacks; h represents the household; i represents the type of inconvenience indicator and $\mathrm{j}$ represents the type of energy source (fuel); min and max represent respectively the minimum and maximum scores for the indicator $\mathrm{i}$ and the fuel $\mathrm{j}$.

Step 2: calculation of the index of energy inconvenience at the energy source (fuel).

After step 1, where the index is calculated for each disadvantage indicator associated with a given energy source, we calculate the overall energy drawbacks for each energy source $\mathrm{j}$ used by a given household $\mathrm{h}$ as the unweighted average distinct signs of discomfort.

$$
E I I_{h i}=\frac{\sum_{i=1}^{n} X_{h i j}}{N_{i j}}
$$

Where, $E I I_{h i}$ is the energy disadvantage index for a given energy source $\mathrm{j}$ in household $\mathrm{h}$. $\mathrm{N}$ is the number of relevant inconvenience indicators for a single given energy source. For traditional biomass, for example, $\mathrm{N}=7$; for kerosene, $\mathrm{N}=6$; for $\mathrm{LPG}, \mathrm{N}=5$.

The advantage of using the average of the inconvenience indices is that the high complication of one type of indicator can be offset by a small disadvantage on another indicator.

Step 3: calculation of the total energy disadvantage index (TEIh) for each household.

We calculate the index of disturbances of households TEIh by aggregating the indices of inconvenience for all the energy sources $\mathrm{j}$ used by a single household $\mathrm{h}$ by weighting them by the share of the energy source (in $\mathrm{kWh}$ ) in the consumption total energy consumption of the household.

$$
T E I_{h}=\sum_{j=1}^{6} \frac{K w_{h j}}{\sum K w_{h j}} * E I I_{h j}
$$

$T E I_{h}$ Represents the total energy disadvantage index for household $\mathrm{h}$ given its specific energy. The ratio $\frac{K w_{h j}}{\sum K w_{h j}}$ represents the energy share in $\mathrm{kWh}$ of a source of energy $\mathrm{j}$ in the total energy consumption of the household in $\mathrm{kWh}$.

Step 4: Define the total threshold of energy drawbacks (TEIT)

To analyze poverty, we need to define the severity threshold, the total energy inconvenience threshold (TEIT), beyond which a household will be defined as energy poor because of the high inconvenience associated with its energy consumption. The disturbance threshold is set at $30 \%$ above the average value of the total energy disturbance. The average value of the total energy inconvenience (TEI) in the sample is 0.249 . The total energy threshold TEIT $_{\mathrm{h}}$ is then calculated as follows:

$$
T E I T_{h}=0,249 * 1,3=0,323
$$

The value of 0.323 gives us the level of threshold of energetic inconvenience. Below this level, the disadvantages experienced by rural households are considered acceptable. Above the threshold, the degree of inconvenience indicates that the household suffers from energy poverty.

Step 5 : calculation of the energy-related disadvantage surplus (EIE) at the household level In this step, the energy inconvenience scores are converted to percentages relative to the threshold so that a meaningful interpretation can be given to the index values. The degree of inconvenience beyond the threshold (TEIT) is termed: excess energy convenience (EIE) calculated as follows:

$$
E I E_{h}=\frac{T E I T_{h}-T E I_{h}}{T E I T_{h}} * 100
$$

$E I E_{h}$ Is expressed in\%. A negative sign indicates that rural households are in an excessive state of disruption while a positive sign indicates that households are in a state of "convenience".

Step 6: Calculating the energy deficit (ES) for households 


$$
E S_{h}=\frac{A E C_{h}-T E R}{T E R} * 100
$$

$E S_{h}$ Is the household h energy deficit; $A E C_{h}$ represents real energy consumption per capita (in $\mathrm{kWh}$ ) using the type of energy source $\mathrm{j}$ in household $\mathrm{h}$; TER represents per capita energy requirements in $\mathrm{kWh}$. The TER is a threshold value in $\mathrm{kWh}$ below which an individual has insufficient energy and is considered to be low in energy. The TER is derived from the literature and can be calculated on the basis of the Tep (tonne of oil equivalent) per year per capita required to reach the level of 0.8 on the Human Development Index (HDI) (Pokharel, 2007).

However, a threshold of 1 toe derived from the HDI is characteristic of advanced economies. It is less relevant for rural communities in developing countries such as Pakistan. For this reason, the authors have adjusted the level of energy consumption to 0.7 toe or $156.55 \mathrm{kWh}$ per week per capita. The deficit is also per capita to allow comparison.

In order for the index of energy nuisance and the energy deficit index to be comparable, so that the same sign indicates energy poverty, the authors subtracted the TER from the $A E C_{h}$ instead of the opposite. Thus, a household energy deficit is represented by negative values.

Step 7: Calculation of the Energy Poverty Index (EPI)

The last step is to combine the two indicators $\left(E I E_{h}\right.$ and $\left.E S_{h}\right)$ into one, which gives us the index of energy poverty of the given household. The PPE is calculated as the unweighted average of the two indicators raised. So we have :

$$
E P I_{h}=\frac{1}{2} *\left(E I E_{h}+E S_{h}\right)
$$

$E P I_{h}$ gives the degree of energy poverty in a household, per capita. Negative values indicate that a household is low in energy, positive values indicate that a household is not energy poor.

Multidimensional Energy Poverty Index (MEPI) (Nussbaumer, Bazilian and Modi, 2012)

Developed on the Oxford Human Poverty and Development Initiative (OPHI), MEPI is a composite index that captures multiple deprivations. Unlike other clues, MEPI focuses on quantifying energy deprivation as opposed to energy access. A number of indices include consumption-based indicators assuming consumption is correlated with development. While recognizing the value of these conglomeratic approaches, a value-free perspective offers a valuable complement by focusing specifically on the poor, providing a more direct indication of the relevant aspects of poverty.

In addition, the authors note that relatively limited attention was paid to capturing aspects related to the quality of energy services provided and / or their reliability, as well as to the notion of accessibility. More importantly, an ideal measure of energy poverty should illuminate the issue through the goal of energy services, which are ultimately important for people and make a difference in their lives. In addition, most measures focus primarily on supply-side or input-oriented data. Better tracking of demand elements is desirable. Finally, the metric algorithm should ideally be able to support variables of different types, such as cardinal and ordinal (categorical). Indeed, in the case of an energy poverty indicator, some variables are likely to be qualitative, such as the type of fuel used.

\section{Delimitation of the perimeter or field of study:}

The authors have limited the scope of this study to the needs of households, while recognizing that other energy needs exist for a society to grow and prosper. Common energy services required in households include:

the kitchen - heating / cooling of the premises - lighting - entertainment / education (radio, television, computer) services provided by household appliances (refrigerator, washing machine and electric geyser) - telecommunications and mechanical power.

\section{Methodology:-}

The methodology used derives from the literature on multidimensional measures of poverty in particular (OPHI) (Alkire and Foster, 2008). MEPI captures all the energy deprivations that can affect a person. It is composed of 5 dimensions representing the basic energy services with 6 indicators.

A person is energy poor or identified as such if the combination of deprivations encountered exceeds a predefined threshold. 
MEPI is the product of a staffing rate (the proportion of people identified as energy poor) and the average intensity of deprivation of the energy poor.

Table 4:- Dimensions and respective variables with thresholds, including relative weights (in parentheses) (Nussbaumer, Bazilian and Modi, 2012).

\begin{tabular}{|c|c|c|c|}
\hline Dimension & $\begin{array}{l}\text { Weight of the } \\
\text { indicator }\end{array}$ & Variables & Poor if \\
\hline \multirow[t]{2}{*}{ Cooking } & $\begin{array}{l}\text { Modern cooking } \\
\text { fuels } \\
(0.2)\end{array}$ & Type of cooking fuel & $\begin{array}{l}\text { Use any other fuel } \\
\text { next to electricity. } \\
\text { LPG, kerosene, natural } \\
\text { gas or biogas }\end{array}$ \\
\hline & $\begin{array}{l}\text { Indoor pollution } \\
(0.2)\end{array}$ & $\begin{array}{c}\text { Cooked or open-fired foods (no } \\
\text { hood / chimney) if you use fuel } \\
\text { other than electricity, LPG, } \\
\text { natural gas or biogas }\end{array}$ & True \\
\hline Lighting & $\begin{array}{c}\text { Access to electricity } \\
(0.2)\end{array}$ & Has access to electricity & False \\
\hline $\begin{array}{l}\text { Services provided by } \\
\text { household appliances }\end{array}$ & $\begin{array}{c}\text { Household appliance } \\
\text { properties } \\
(0.13)\end{array}$ & Has a refrigerator & False \\
\hline Entertainment / Education & $\begin{array}{c}\text { Properties of } \\
\text { entertainment / } \\
\text { education devices } \\
(0.13) \\
\end{array}$ & has a radio or television & False \\
\hline Communication & $\begin{array}{c}\text { Telecommunication } \\
\text { means } \\
(0,13)\end{array}$ & $\begin{array}{c}\text { Has a phone line or a mobile } \\
\text { phone }\end{array}$ & False \\
\hline
\end{tabular}

Formally, MEPI measures energy poverty in $\mathrm{d}$ variables for a population of $\mathrm{n}$ individuals. $\mathrm{Y}=\left[y_{i j}\right]$ represents the matrix of realizations of dimension $\mathrm{n} * \mathrm{~d}$ for $\mathrm{i}$ persons through $\mathrm{j}$ variables. $y_{i j}>0$ designates the individual realization $\mathrm{i}$ in the variable $\mathrm{j}$. Thus, each line vector $y_{i}=\left(y_{i 1}, y_{i 2}, \ldots \ldots, y_{i d}\right)$ represents the individual realization $\mathrm{i}$ in the different variables, and each column vector $y_{j}=\left(y_{1 j}, y_{2 j}, \ldots \ldots, y_{n j}\right)$ gives the distribution of achievements in variable $\mathrm{j}$ through individuals. The methodology allows the indicators to be weighted unevenly if desired. A weighting vector $\mathrm{W}$ is composed of elements $W_{j}$ corresponding to the weight applied to the variable $\mathrm{j}$. The authors define:

$$
\sum_{j=1}^{d} W_{j}=1
$$

For sensitivity analysis by taking some of the uncertainty associated with weight assignment, they applied probabilistic functions to respective weights. The authors define the functions using the deterministic weights given in the table as the mean of the respective normal probabilistic functions and set the standard deviation to 0.02.They define $Z_{j}$ as the deprivation limit in the variable $\mathrm{j}$, and then identify all individuals without variables. Let $\mathrm{g}=\left[g_{i j}\right]$ be the deprivation matrix whose typical element g_ijis defined by $g_{i j}=W_{j}$ when $y_{i j}<z_{j}$ and $g_{i j}=0$ when $y_{i j} \geq z_{j}$.

In the case of MEPI, since the element of the achievement matrix is strictly non-numeric in nature, the threshold is defined as a set of conditions to be fulfilled (see Table 3). The entry ij of the matrix is equivalent to the weight variable $W_{j}$ when a person is deprived of the variable $\mathrm{j}$, and zero (0) when the person is not deprived. Then, a column vector $\mathrm{C}$ of the deprivation counts is constructed, where the ith entry $C_{i}=\sum_{j=1}^{d} g_{i j}$ represents the sum of the weighted deprivations suffered by the person i.

It should be noted here that the technique by which weights are summarized as opposed to a weighted score is not new in that it has been applied to a number of multicriteria methodologies. 
They then identify energy-poor people from a multidimensional point of view by defining a threshold $k>0$ and applying it across the column vector, and consider a person low in energy if his weighted deprivation count exceeds $\mathrm{k}$. Therefore, $C_{i}(k)$ is set to 0 when $C_{i} \leq k$ and is equal to $C_{i}$ when $C_{i}>k$. Thus, c (k) represents the censored vector of deprivation counts, and it is different from $\mathrm{c}$ in that it does not count deprivation for those who are not identified as poor in multidimensional energy.

Finally, they calculate the ratio of personnel $\mathrm{H}$ which represents the proportion of people considered as energy poor. With q as the number of energy poor people (where $C_{i}>k$ ) and $\mathrm{n}$ the total, we have $H=\frac{q}{n}$; which is the index of multidimensional energy poverty.

The average of censored weighted deprivation accounts $\mathrm{C}_{\mathrm{i}}(\mathrm{k})$ represents the intensity of multidimensional energy poverty A.

More easily, we can calculate:

$$
A=\sum_{i=1}^{n} \frac{C_{i}(k)}{q}
$$

MEPI includes information on the index and the intensity of energy poverty and is defined as:

$$
\text { MEPI }=\mathrm{H} * \mathrm{~A}
$$

Energy poverty index (Bonatz et al., 2018)

It is one of the most recent energy poverty indices, it characterizes and compares energy poverty in China and Germany over the last decade. This index takes into account access and affordability indicators; describing recent low carbon development strategies and their effects on energy efficiency and production. It highlights the links between energy poverty and low carbon development and identifies the opportunities and barriers to energy poverty.

Comprehensive Energy Poverty Index (CEPI)(Khanna et al., 2019)

Energy availability, accessibility and affordability are the main causes of energy poverty for several authors. However, existing measures of energy poverty do not always address these three factors together. It is within this framework that a new indicator for measuring energy poverty is being developed. This indicator named Comprehensive Energy Poverty Index (CEPI) is a composite index that measures the extent of energy poverty in ASEAN countries and India, and takes into account the three factors listed above. Cambodia is found to be the most energy-poor country among the countries surveyed and Thailand is the least energy-poor country.

Synthesis

Table 5 below summarizes the various indices mentioned above and the respective authors.

Table 5:- Summary of energy poverty indicators.

\begin{tabular}{|l|c|c|}
\hline \multicolumn{1}{|c|}{ Index category } & Index & Authors \\
\hline Unidimensional Indices & Foster et al Index & $\begin{array}{c}\text { (Foster, Tre and } \\
\text { Wodon, 2000) }\end{array}$ \\
\hline $\begin{array}{l}\text { Indicators consisting of a set of individual indicators } \\
\text { or dashboards }\end{array}$ & Two-dimensional measurement & (Pachauri et al., 2004) \\
\cline { 2 - 3 } Composite indices & IEDD & (IAEA, 2008) \\
\cline { 2 - 3 } & EDI & (IEA, 2010) \\
\cline { 2 - 3 } & EPI & $\begin{array}{c}\text { (Mirza and Szirmai, } \\
\text { 2010) }\end{array}$ \\
\cline { 2 - 3 } & MEPI & $\begin{array}{c}\text { (Nussbaumer, } \\
\text { Bazilian and Modi, } \\
\text { 2012) }\end{array}$ \\
\cline { 2 - 3 } & & (Bonatz et al., 2018) \\
\cline { 2 - 3 } & Ehanna et al., 2019) \\
\cline { 2 - 3 }
\end{tabular}

Each indicator has specific interests. But what determines the choice of an indicator is the availability of energy data (IEA, 2010). Depending on the information available, the appropriate indicator is chosen. 
Taking into account all informations contained in Table 3 and section 6, a new composite energy poverty measurement index will be developped. That novel indicator'll derived from (Mirza and Szirmai, 2010) index and include equipments energy efficiency, energy source transportation cost and exposition time at energy source.

\section{Energy poverty in Benin:}

The first measure of energy poverty in Benin was carried out in 2010 by the IEA with the Energy Development Index (EDI) as a tool. This measure revealed that Benin with an EDI score around 0.111 is energy poor (IEA, 2010). Then, MEPI's multidimensional measurement of energy poverty in 2011 with MEPI indicates that Benin with a score of 0.83 is low in energy (Nussbaumer, Bazilian and Modi, 2012). These measures are even more true than in Benin, three main sources of energy are used including biomass, petroleum products and electricity. The traditional use of biomass (firewood and charcoal) is the primary source of energy with about $51 \%$ of the total energy balance, or more than $70 \%$ of household energy consumption. Petroleum products come in second place with a share of about $46 \%$ of the total energy balance and in third position electricity with a share of about $3 \%$ in the total energy balance with total external dependence for supplies (MCA-Bénin, 2017). So, according to energy poverty defined as access to modern and affordable energy sources, we can conclude that about 68 percent of Benin people are poor in energy because they lack access to electricity. Moreover, traditional use of biomass as energy source in household has negative impacts on human health and the socio-economic conditions of households. The lack of access to electricity is a manifestation of energy poverty. Injustices based on energy are not perceived in the same way by region of the country, by social category and by gender (AFD, 2017 ; EKOUEVI, 2011). The concept of energy poverty has therefore been the subject of very little study in Benin. The tools available in the literature for measuring energy poverty are not always the most appropriate for local realities.

\section{Conclusion and Future Scope:-}

Energy poverty is a multidimensional concept and there is no standard definition. Depending on the approach used, energy poverty can be defined differently. This phenomenon results from the combined effect of low income, high energy costs and inefficiency or low energy efficiency of equipment. There are several categories of indicators that measure energy poverty, but each of them has the advantages and limitations noted above. In view of the SWOT analysis performed, the composite indices appear to be more appropriate and flexible to handle. What determines the choice of an indicator is the availability of energy data. The concepts of energy justice and energy poverty are embryonic in West Africa in general and in Benin in particular. The manifestations of energy injustices and energy poverty are observed in Benin and these injustices are not perceived in the same way according to the region of the country, according to the social category and according to the gender. Energy efficiency seems to be the most tangible and realistic way to take action to improve energy poverty and energy justice. Indeed, Benin has a large pool that could help improve energy justice if energy efficiency measures and policies are implemented. The next steps in this study will be to develop a composite index of energy poverty measurement adapted to the context of Benin and the West African subregion, which includes the energy efficiency of the equipment used. This index will be used on a sample of the Beninese population to measure energy poverty in relation to the energy efficiency of equipment.

\section{Acknowledgement:-}

Funding source:We would like to thank the International Development Research Centre (IDRC) which financed this study through project number [6156] entitled: "Optimal energy efficiency strategies to promote energy justice and low-carbon development" carried out by ECONOLER in Benin.

\section{Reference:-}

1. AFD (2017) 'Boîte à outils genre'.

2. AGECC (2010) 'Energy for a Sustainable Future', (April).

3. Bagenal, F. (2017) 'C olorado E uropa L angmuir P robe', pp. 1-11.

4. Bala, B. K. (1991) 'A MODEL FOR THE QUALITY OF LIFE AS A', 16(4), pp. 739-745.

5. Bickerstaff, K., Bulkeley, H. and painter, J. (2009) 'Justice, nature and the city', International Journal of Urban and Regional Research, 33(3), pp. 591-600. doi: 10.1111/j.1468-2427.2009.00858.x.

6. Boardman, B. (2012) Fuel poverty, International Encyclopedia of Housing and Home. Elsevier Ltd. doi: 10.1016/B978-0-08-047163-1.00552-X.

7. Bonatz, N. et al. (2018) 'PT', Energy \& Buildings. Elsevier B.V. doi: 10.1016/j.enbuild.2018.09.042.

8. Davis, M. (1998) 'Rural household energy consumption evidence from', 26(3), pp. 207-217. 
9. Devalière, I. (2007) 'Comment prévenir la précarité énergétique? Situation actuelle et risques inhérents à la libéralisation du service de 1 â€TM énergie', pp. 137-143.

10. EKOUEVI, D. (2011) 'Rapport d'étude', 41(0), p. 2018.

11. EPEE (2008) 'La question de la précarité énergétique dans le logement social public', pp. 4-9.

12. EPEE (2009) 'Diagnostic des causes et conséquences de la France, Italie et Royaume-Uni'.

13. Foster, V., Tre, J. and Wodon, Q. (2000) 'Energy prices, energy efficiency, and fuel poverty 1 Vivien Foster, Jean-Philippe Tre, and Quentin Wodon World Bank September 2000', (September).

14. Heffner, G. and Campbell, N. (2011) 'Evaluating the co-benefits of low-income energy-efficiency programmes', Environment, (January), pp. 27-28.

15. Heffron, R. J. and McCauley, D. (2014) 'Achieving sustainable supply chains through energy justice', Applied Energy. Elsevier Ltd, 123, pp. 435-437. doi: 10.1016/j.apenergy.2013.12.034.

16. Hosier, R. H. and Kipondya, W. (1993) 'Urban household energy use in Tanzania Prices, substitutes and poverty', pp. 454-473.

17. IAEA (2008) 'Indicateurs énergétiques du développement durable : lignes directrices et méthodologies'.

18. IEA (2010) 'EnErgy povErty How to make modern', Outlook, (September).

19. IEA (2017) WEO-2017 Special Report: Energy Access Outlook.

20. Ii, C. et al. (2010) 'Articles de la loi ${ }^{\circ}{ }^{\circ} 2010-788$ du 12 juillet 2010 portant engagement national pour 1 ' environnement ( dite grenelle 2 ), traitant de la Trame verte et bleue'.

21. James Foster (1984) 'A Class of Decomposable Poverty Measures Author ( s ): James Foster, Joel Greer and Erik Thorbecke Published by: The Econometric Society Stable URL : http://www.jstor.org/stable/1913475 .', 52(3), pp. 761-766.

22. Jenkins, K. et al. (2014) 'Energy Justice, a Whole Systems Approach', Queen's Political Review, II(2), pp. 7487.

23. Jenkins, K. et al. (2016) 'Energy justice: A conceptual review’, Energy Research and Social Science. Elsevier Ltd, 11, pp. 174-182. doi: 10.1016/j.erss.2015.10.004.

24. Jenkins, K., McCauley, D. and Warren, C. R. (2017) 'Attributing responsibility for energy justice: A case study of the Hinkley Point Nuclear Complex', Energy Policy. Elsevier Ltd, 108(December 2016), pp. 836-843. doi: 10.1016/j.enpol.2017.05.049.

25. Johansson, T. and G. J. (2002) Energy for sustainable development a policy agenda.

26. Joroff, A. (2017) 'Energy Justice: What It Means and How to Integrate It Into State'.

27. Khanna, R. A. et al. (2019) 'Comprehensive energy poverty index: Measuring energy poverty and identifying micro-level solutions in South and Southeast Asia', Energy Policy. Elsevier Ltd, 132(November 2018), pp. 379-391. doi: 10.1016/j.enpol.2019.05.034.

28. LaBelle, M. C. (2017) 'In pursuit of energy justice', Energy Policy. Elsevier Ltd, 107(November 2016), pp. 615-620. doi: 10.1016/j.enpol.2017.03.054.

29. Leach, G. (1987) 'Energy and the Urban Poor’, I(I), pp. 31-38.

30. Legendre, B. and Ricci, O. (2014) 'Measuring fuel poverty in France: Which households are the most fuel vulnerable?', Energy Economics, 49, pp. 620-628. doi: 10.1016/j.eneco.2015.01.022.

31. MCA-Bénin (2017) 'Plan Directeur d 'Electrification Hors Réseau environnement propice à 1 ' électrification'.

32. McCauley, D. et al. (2013) 'Advancing energy justice: the triumvirate of tenets', International Energy Law Review, 32(3), pp. 107-110. Available at: https://dspace.stir.ac.uk/bitstream/1893/18349/1/IELR 2013.pdf.

33. Millenium Challenge Account (2018) 'Plan d' Intégration Sociale et Genre'.

34. Mirza, B. and Szirmai, A. (2010) 'Working Paper Series', (31), pp. 1-41.

35. Nussbaumer, P., Bazilian, M. and Modi, V. (2012) 'Measuring energy poverty: Focusing on what matters', Renewable and Sustainable Energy Reviews. Elsevier Ltd, 16(1), pp. 231-243. doi: 10.1016/j.rser.2011.07.150.

36. Nzobadila, P. G. (2017) 'Commission Africaine de 1 â€TM Energie ( AFREC ) Document sur la Pauvreté énergétique en Afrique', pp. 1-8.

37. Pachauri, S. et al. (2004) 'On measuring energy poverty in Indian households', World Development, 32(12), pp. 2083-2104. doi: 10.1016/j.worlddev.2004.08.005.

38. Palmer, G. . et al (2008) Cold and Poor: An analysis of the link between fuel poverty and low income.

39. Papada, L. and Kaliampakos, D. (2018) 'A Stochastic Model for energy poverty analysis', Energy Policy. Elsevier Ltd, 116(December 2017), pp. 153-164. doi: 10.1016/j.enpol.2018.02.004.

40. Sari et al. (2017) 'a Social Sciences and Humanities Cross-Cutting Theme Report', Energy justice.

41. Simcock, N. and Mullen, C. (2016) 'Energy demand for everyday mobility and domestic life: Exploring the justice implications', Energy Research and Social Science. Elsevier Ltd, 18, pp. 1-6. doi: 10.1016/j.erss.2016.05.019. 
42. Sovacool, B. K. and Dworkin, M. H. (2015) 'Energy justice: Conceptual insights and practical applications', Applied Energy. Elsevier Ltd, 142, pp. 435-444. doi: 10.1016/j.apenergy.2015.01.002.

43. Sustainable Energy For All Global Tracking Framework (2017) 'Progress toward Sustainable Energy 2017', International Bank for Reconstruction and Development, The World Bank and the International Energy Agency, Washington DC, 1(1), pp. 1-40. doi: 10.1596/ 978-1-4648-1084-8.

44. The UK Fuel Poverty Strategy (2003) 'Ist Annual Progress Report'.

45. UN Energy and UN-Energy (2005) 'The energy challenge for achieving the Millennium Development Goals', United Nations, p. 20. Available at: http://cn.unhabitat.org/downloads/docs/920_88725_The Energy challenge for achieving the millenium development goals.pdf.

46. United Nations (1948) 'Universal Declaration of Human Rights', Universal Declaration of Human Rights, pp. 1-72. doi: 10.1017/CBO9781107415324.004.

47. United Nations (2015) 'Sustainable Development Goals'. 